\title{
Sken\&agraphie
}

skilingraphil Coulisses des arts du spectacle et des scènes

émergentes

4 | Automne 2016

Médée à l'opéra

\section{Trois Médée au Théâtre des Champs-Élysées. Krzysztof Warlikowski, Pierre Audi \& Sasha Waltz}

\section{Ruth Walz, Sebastian Bolesch et Vincent Pontet}

\section{OpenEdition \\ Journals}

\section{Édition électronique}

URL : http://journals.openedition.org/skenegraphie/1297

DOI : 10.4000/skenegraphie.1297

ISSN : 2553-1875

\section{Éditeur}

Presses universitaires de Franche-Comté

\section{Édition imprimée}

Date de publication : 31 décembre 2016

Pagination : non paginé

ISBN : 978-2-84867-584-8

ISSN : $1150-594 X$

\section{Référence électronique}

Ruth Walz, Sebastian Bolesch et Vincent Pontet, «Trois Médée au Théâtre des Champs-Élysées.

Krzysztof Warlikowski, Pierre Audi \& Sasha Waltz », Sken\&agraphie [En ligne], 4 | Automne 2016, mis en ligne le 05 juillet 2017, consulté le 25 avril 2019. URL : http://journals.openedition.org/ skenegraphie/1297; DOI : 10.4000/skenegraphie.1297

Ce document a été généré automatiquement le 25 avril 2019.

Presses universitaires de Franche-Comté 


\section{Trois Médée au Théâtre des Champs- Élysées. Krzysztof Warlikowski, Pierre Audi \& Sasha Waltz}

Ruth Walz, Sebastian Bolesch et Vincent Pontet

La Médée de Charpentier mise en scène par Pierre Audi

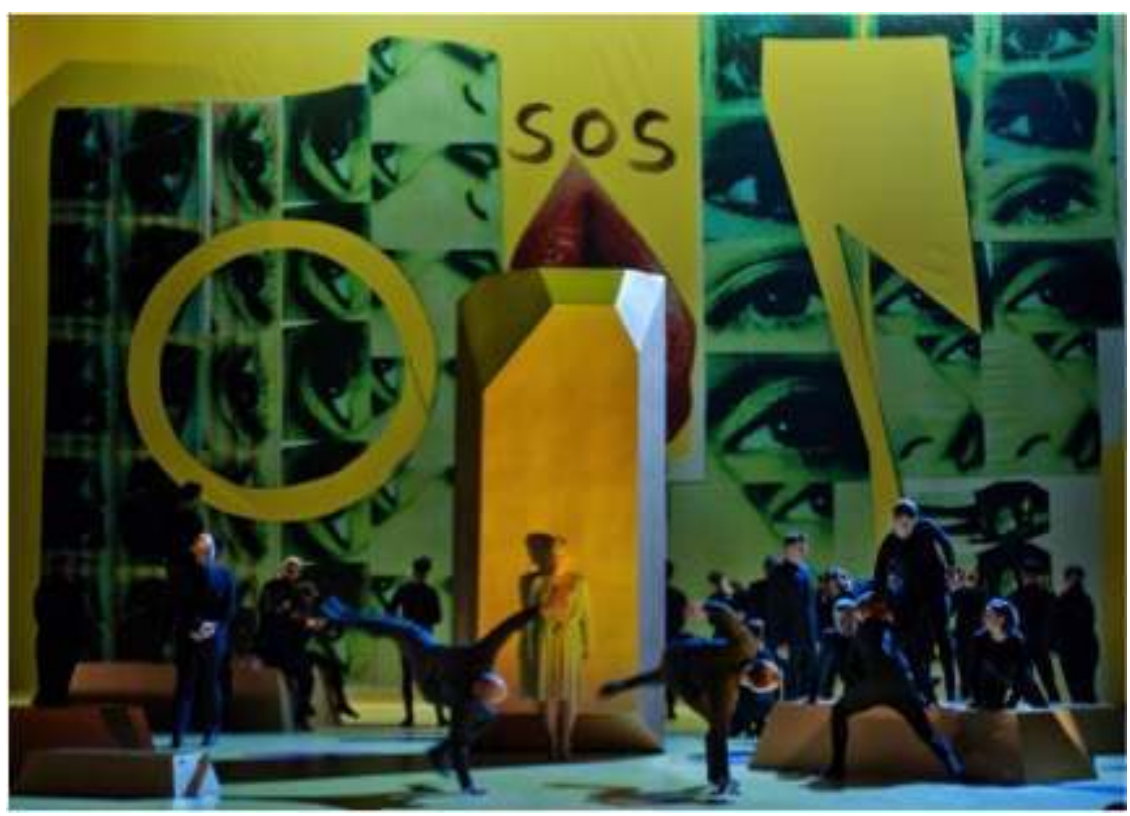

Charpentier, Médée, mise en scène Pierre Audi, Théâtre des Champs-Élysées, 2012. (c) Ruth Walz. 


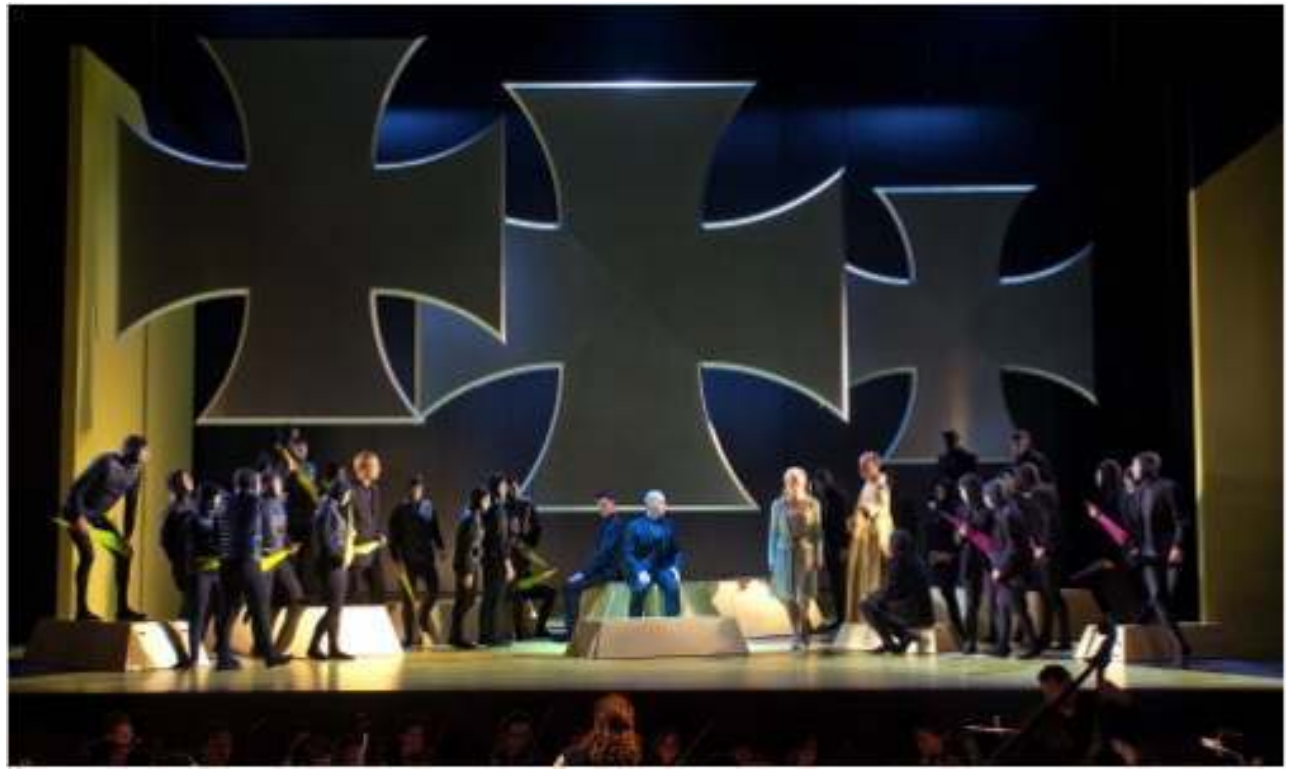

Charpentier, Médée, mise en scène Pierre Audi, Théâtre des Champs-Élysées, 2012. (c) Ruth Walz.

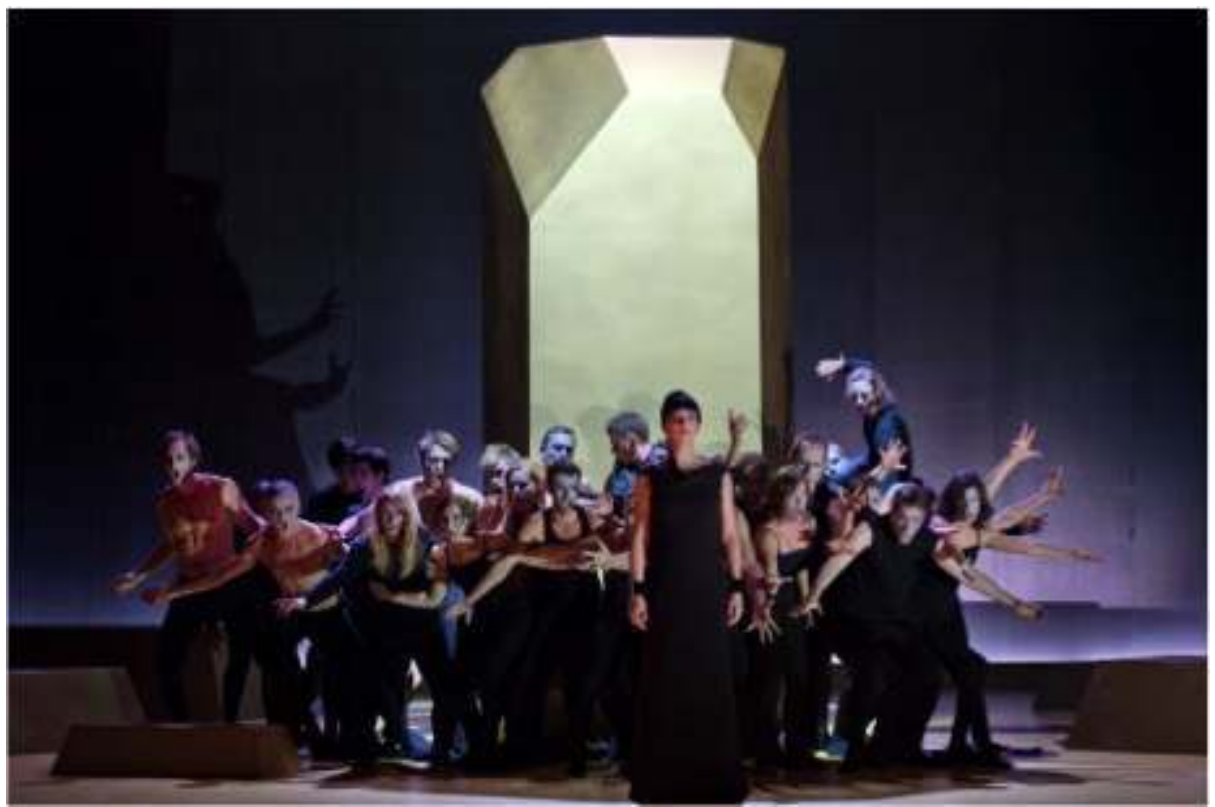

Charpentier, Médée, mise en scène Pierre Audi, Théâtre des Champs-Élysées, 2012. (c) Ruth Walz. 


\section{La Medea de Dusapin chorégraphiée par Sasha Waltz}

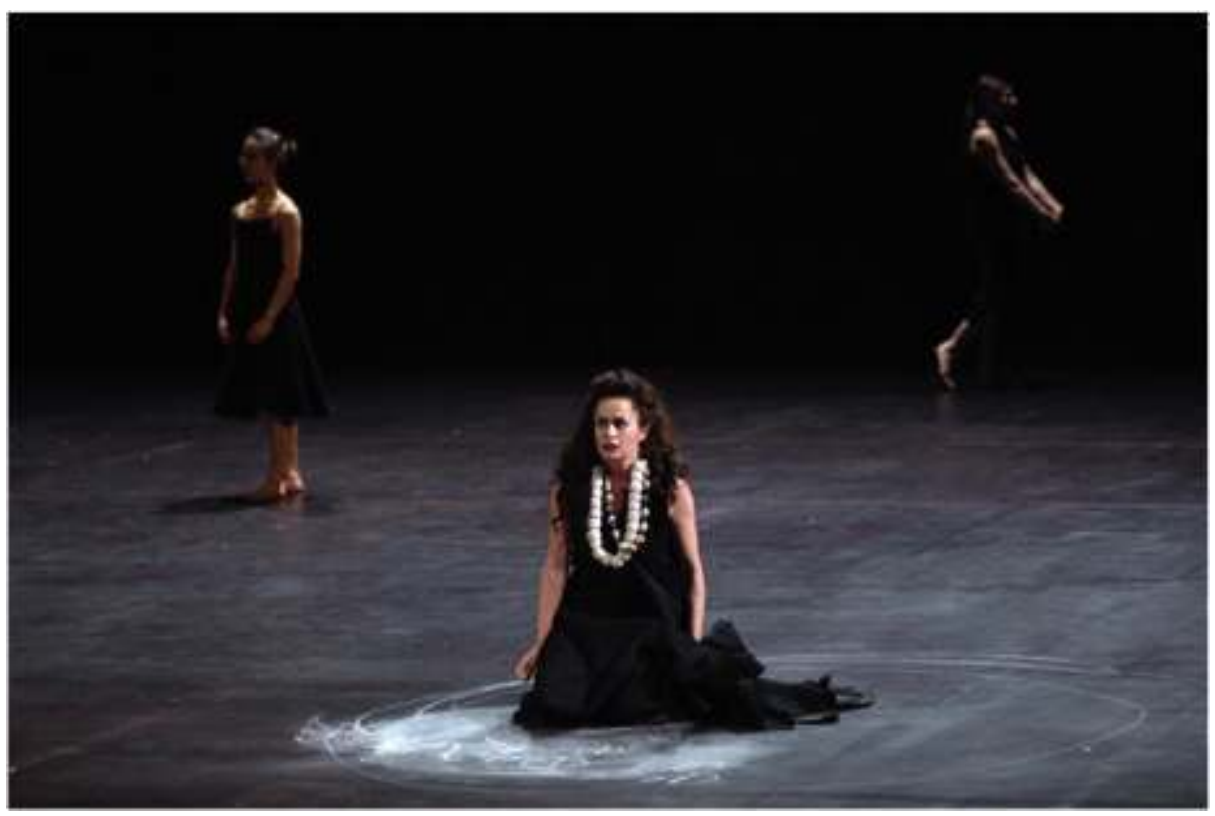

Dusapin, Medea, chorégraphie Sasha Waltz, Théâtre des Champs-Élysées, 2012. (c) Sebastian Bolesch.

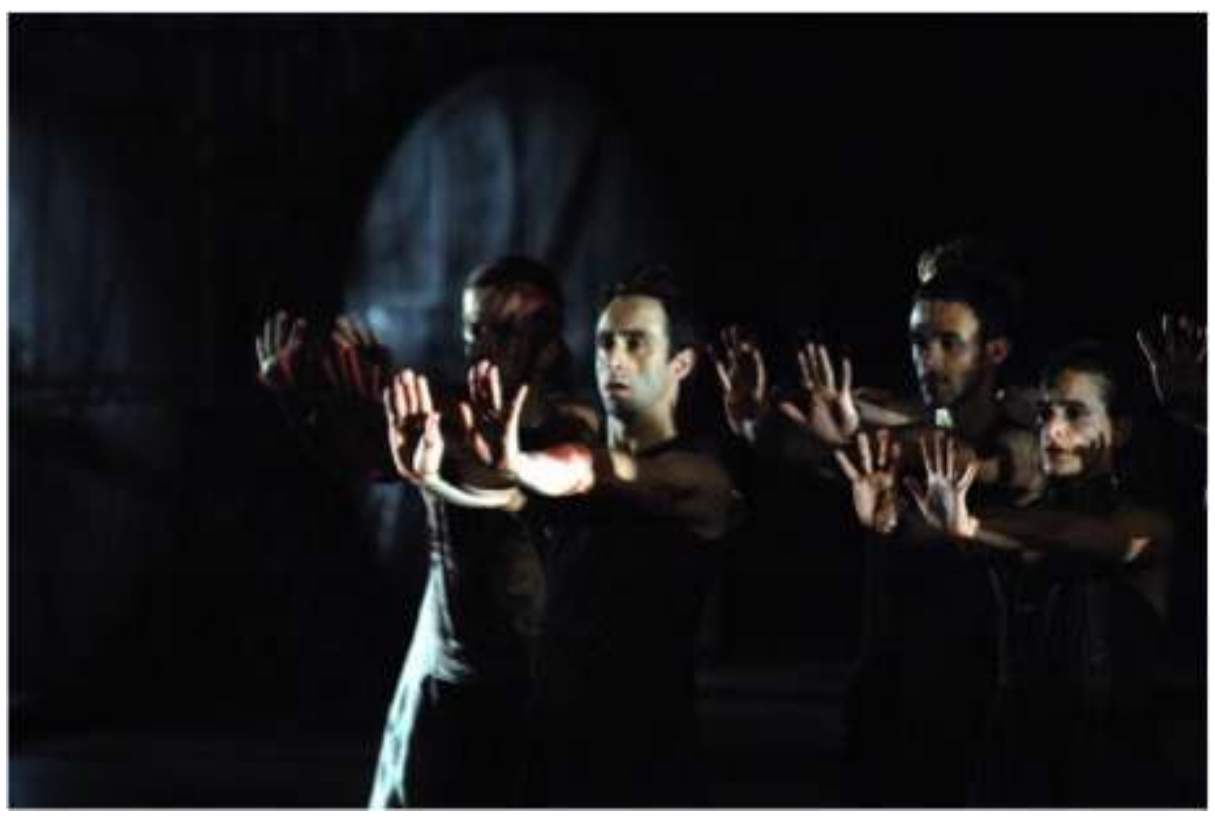

Dusapin, Medea, chorégraphie Sasha Waltz, Théâtre des Champs-Élysées, 2012. (C) Sebastian Bolesch. 


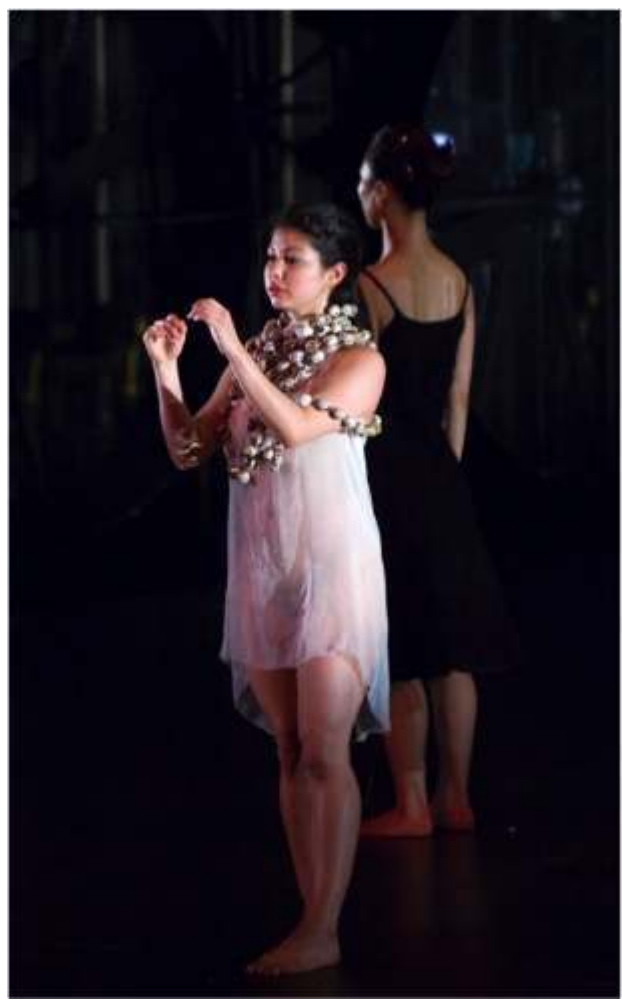

Dusapin, Medea, chorégraphie Sasha Waltz, Théâtre des Champs-Élysées, 2012. (c) Sebastian Bolesch.

\section{La Médée de Cherubini mise en scène par Krzysztof Warlikowski}

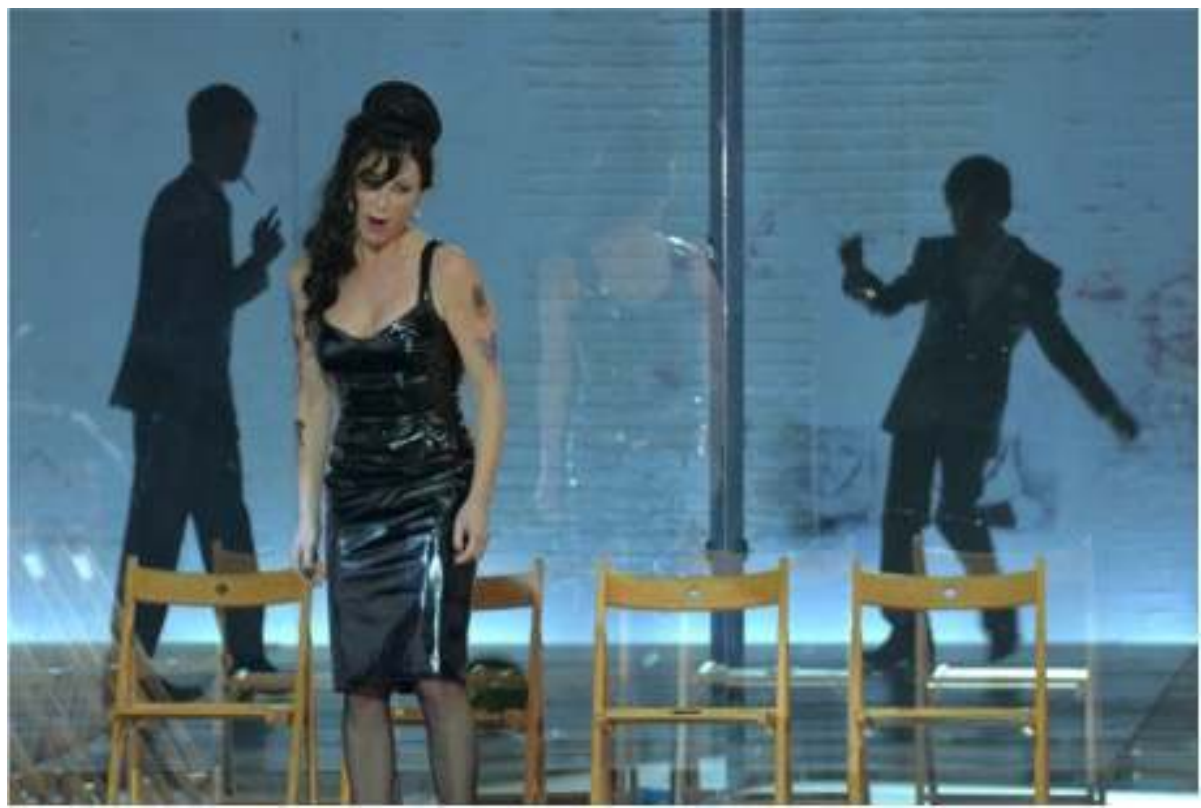

Cherubini, Médée, mise en scène Krzysztof Warlikowski, Théâtre des Champs-Élysées, 2012 (c) Vincent Pontet. 


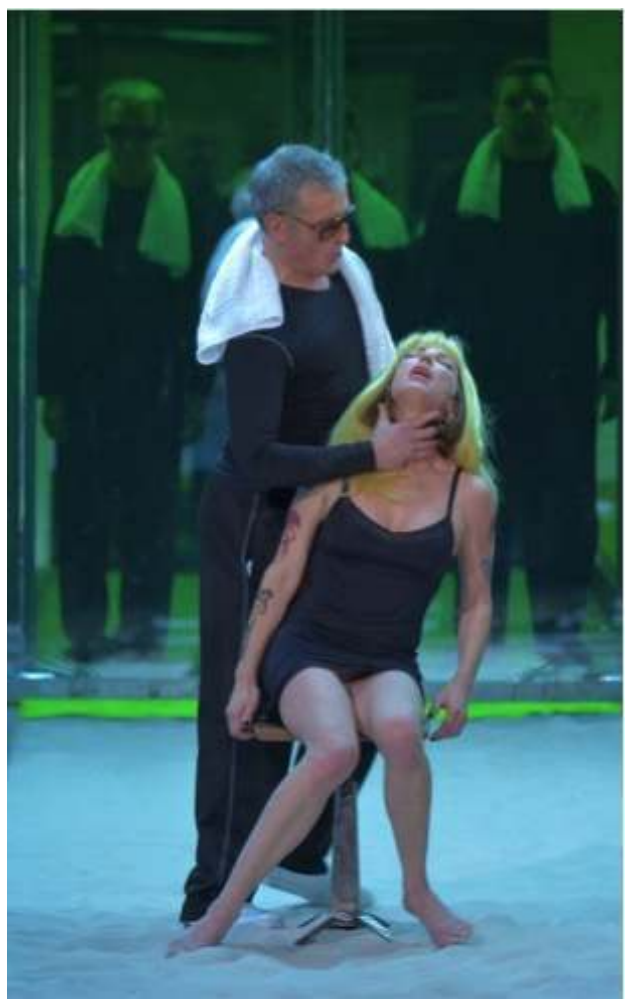

Cherubini, Médée, mise en scène Krzysztof Warlikowski, Théâtre des Champs-Élysées, 2012. (c) Vincent Pontet.

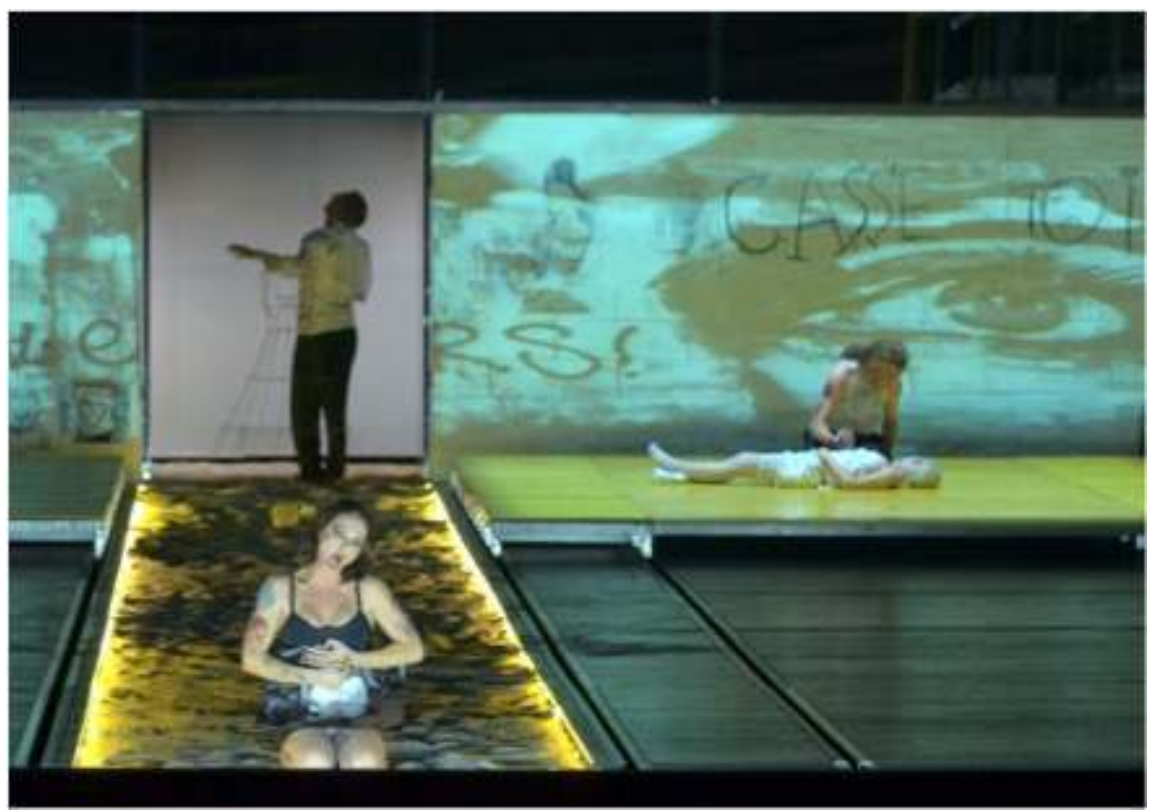

Cherubini, Médée, mise en scène Krzysztof Warlikowski, Théâtre des Champs-Élysées, 2012. (c) Vincent Pontet. 